FERMILAB-TM-1731

\title{
Initial Results from 50mm Short SSC Dipoles at Fermilab
}

R. C. Bossert, J. S. Brandt, J. A. Carson, K. Coulter, S. Delchamps,

K. D. Ewald, H. Fulton, I. Gonczy, S. A. Gourlay, T. S. Jaffery, W. Kinney, W. Koska, M. J. Lamm, J. B. Strait, M. Wake

Technical Support Section

M. Gordon, N. Hassam, R. Sims, M. Winters

SSC Magnet Project

Fermi National Accelerator Laboratory

P.O. Box 500

Batavia, Illinois 60510

March 1991

* Submitted at the Third Annual International Industrial Symposium on the Super Collider. 
INITIAL RESULTS FROM 5OMM SHORT SSC DIPOLES AT FERMILAB

R. C. Bossert, J. S. Brandt, J. A. Carson, K. Coulter, S. Delchamps, K. D. Ewald, H. Fulton, I. Gonczy, S. A. Gourlay, T. S. Jaffery, W. Kinney, W. Koska, M. J. Lamm, J. B. Strait, M. Wake

Fermi National Accelerator Laboratory

Technical Support Section

Batavia, Illinois 60510

M. Gordon, N. Hassan, R. Sims, M. Winters

Fermi National Accelerator Laboratory

SSC Magnet Project

Batavia, Illinois 60510

\section{ABSTRACT}

Several short model SSC $50 \mathrm{~mm}$ bore dipoles are being built and tested at Fermilab. Mechanical design of these magnets has been determined from experience involved in the construction and testing of $40 \mathrm{~mm}$ dipoles. Construction experience includes coil winding, curing and measuring, coil end part design and fabrication, ground insulation, instrumentation, collaring and yoke assembly. Fabrication techniques are explained and construction problems are discussed. Similarities and differences from the $40 \mathrm{~mm}$ dipole tooling and magnet components are outlined. Test results from the first models are presented.

\section{INTRODUCTION}

A series of SSC short model dipoles are being built for the purpose of analyzing the Fermilab design and construction methods before incorporating them in long models. Design of these magnets is described in detail in Reference 1. A summary of the most important features is listed in Table 1. Specific features of short models change as the program progresses. New design features are tried in short models before being incorporated into full length magnets. 
1. W6733 Cross-section

2. Cable Insulation System Consisting of Kapton Type-H Film Surrounded by Epoxy Impregnated Fiberglass Tape

3. Machined G-10 Coil End Parts Made to a Geometry Determined by Fermilab Produced Computer Programs

4. Coils Cured Using Closed Cavity Mold With Hydraulic Pressure on Ends

5. Ground Insulation Consisting of all .005 inch Kapton With Collaring Shoes but No Collaring Shims

6. SSCL Style Strip Heater

7. One Strain Gage Pack

8. External Inner to Outer Coil Splices

9. Collet Style End Clamps

10. 57 Voltage Taps

11. Vertically Split Yoke

12. Precision Skin With Full Length Fiducial

13. Shell Gauges Mounted to Outside of Skin

14. 1.5 Inch Thick End Plate Welded Directly to Skin

15. Bullet Style End Force Gauges on Return End

One magnet (DSA321) has been completed and tested to date. Two more magnets (DSA322 and DSA323) are partially complete.

\section{DSA321 ASSEMBLY HISTORY}

The first step in fabricating Fermilab coils is to preform the splice area. Preforms are made in mechanical fixtures which confine the cable to a precise shape. The cable is filled with solder while confined in the fixture. Maintaining dimensional consistency in the preform was a problem in the $40 \mathrm{~mm}$ program.

Preforming for DSA321 went well. The preformed area was better than the $40 \mathrm{~mm}$, but still inconsistent. Preformed cable was wider in some areas than the untinned bare cable by as much as .030 inches. This caused extra space to be needed in the pocket of the collet end clamp which accepts the splice. Green putty was used to fill the extra space. New preform fixtures are being developed to correct this problem.

Winding tension was 85 to $87 \mathrm{lbs}$. for inner coils and 85 to $90 \mathrm{lbs}$. for outer coils. These winding tensions worked well. However, there is some concern that these tensions will cause an unacceptable amount of longitudinal "springback" when winding long magnets. Springback occurs when a cured coil is removed from the mold. Smaller winding tensions will be attempted in future $50 \mathrm{~mm}$ coil winding.

Coil winding, curing and collaring tooling is modeled closely after the $40 \mathrm{~mm}$ SSC tooling 5,16 with one significant exception: $40 \mathrm{~mm}$ molds and mandrels were constructed from $1 / 16$ inch thick steel laminations. On the $50 \mathrm{~mm}$ short tooling the laminations have been replaced by two inch thick sections made by a wire EDM process. EDM'd sections were chosen for the short magnets as there was not enough time to produce laminations and still meet the short magnet schedule. The EDM'd tooling will be replaced by laminated tooling when it is available.

Coil end parts were designed and manufactured according to geometry created by computer programs at Fermilab. A "developable surface/grouped" configuration was chosen. 5,12,13,14 Conductor placement on the ends was generally very good. The end parts did not lift from the mandrel surface during winding by more than $1 / 16$ inch as shown in Fig. 1 . It was, however, difficult to completely close the ends longitudinally. Coil ends were as much as $1 / 8$ inch longer than the end part design allows. This results in wedge gaps as shown in Fig. 2 . The solution will involve a combination of better end part preloading during winding and curing and adjustment of the cable paths in the end parts. ${ }^{2}$ 


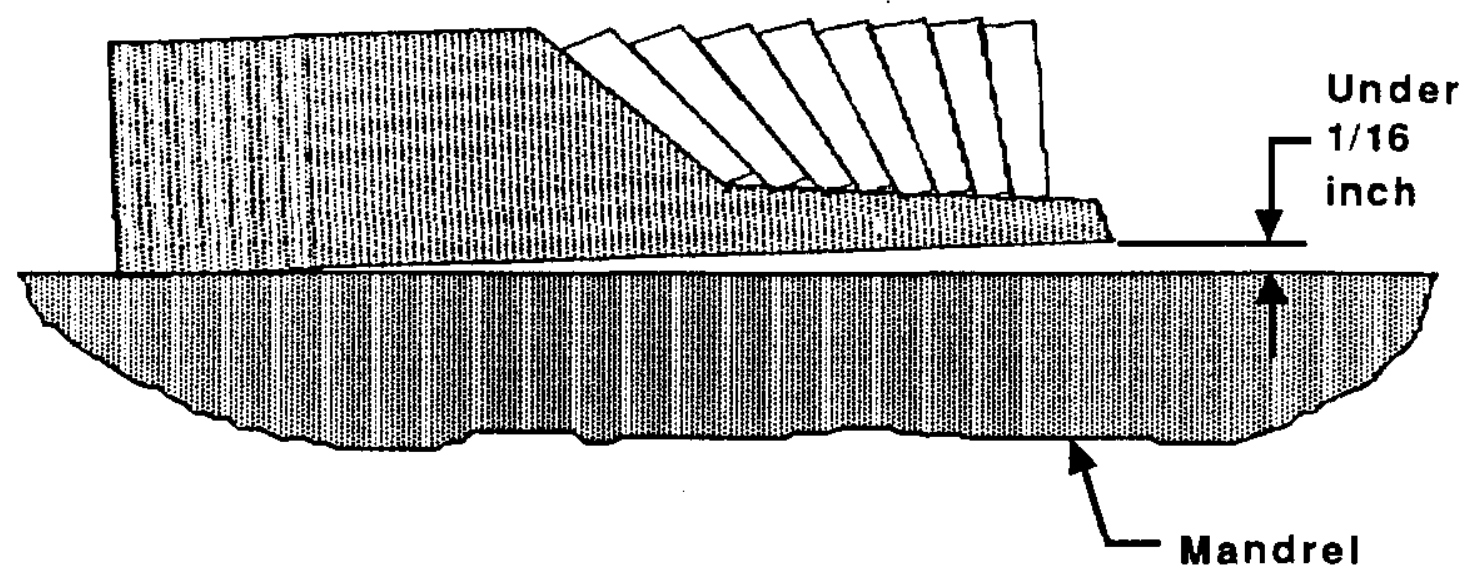

Fig. 1. End Parts Lift During Winding

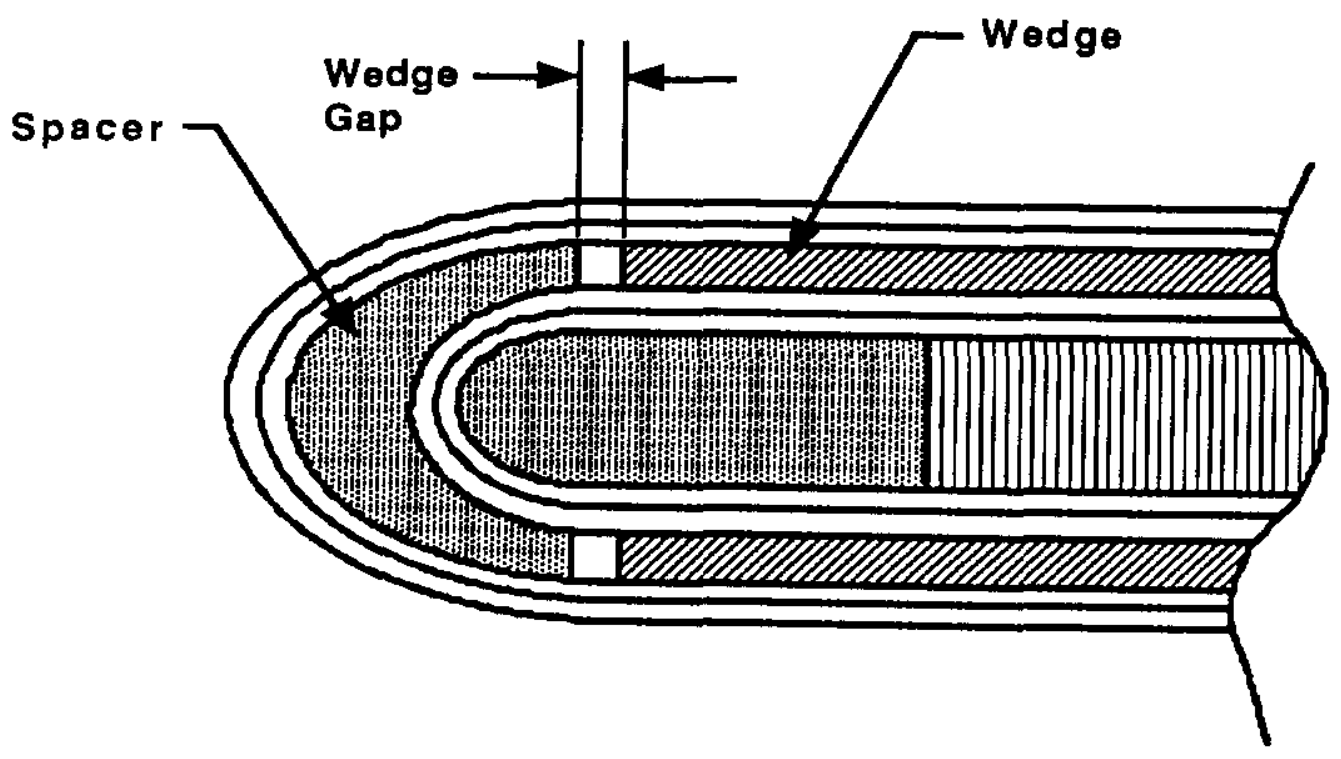

Fig. 2. Wedge Gaps

The wedge closest to the parting plane on the inner coil often scrapes against the retainer as the coil is compressed into the mold. This causes the glass tape and insulation to be scraped off the wedge. This problem is likely due to the geometry of the cross-section. The wedge has a very large angle and must rotate significantly in the mold to be pushed into position. The large angle also causes the wedge to be forced outward radially when pressure is applied in the curing mold. Improved low friction mold release may partially relieve the problem. It is not likely that this problem can be completely eliminated without a change in the cross-section.

Curing pressures can only be inferred from the total force applied by the press cylinders. Three forces are applied to the coils: mandrel (radial) pressure, azimuthal pressure and end pressure. Mandrel force applied was $666 \mathrm{lbs}$. per linear inch. Azimuthal force applied was $13000 \mathrm{lbs}$./linear inch or $13000 \mathrm{psi}$ for inner coils and $13700 \mathrm{psi}$ for outer coils. It is uncertain how much of the azimuthal force is applied to the coils and how much is reacted by the tooling. This relationship also changes when the coil is heated. Real curing pressures are, therefore, smaller than the numbers stated above by an unknown amount. End loading was 1500 lbs. 
Coil size measurements are shown in Figs. 4 and 5. One graph is shown for inner coils and one for outers. Coil sides are labeled "Quadrant I/II" and "Quadrant II/IV" and are oriented as shown in Fig. 3. Coils are measured by comparing them to a steel master that is equal to the design size of a coil quadrant.

Inner coils are roughly .010 inches larger than the master at 12000 coil psi. Outer coils are about .006 inches larger than the master at the same pressure. No material was added or removed at the poles to adjust preload. Collar deflections allow the real preloads to be smaller than the values which would be predicted from the coil measurements. Size variations within coils are comparable to the $40 \mathrm{~mm}$ coils.
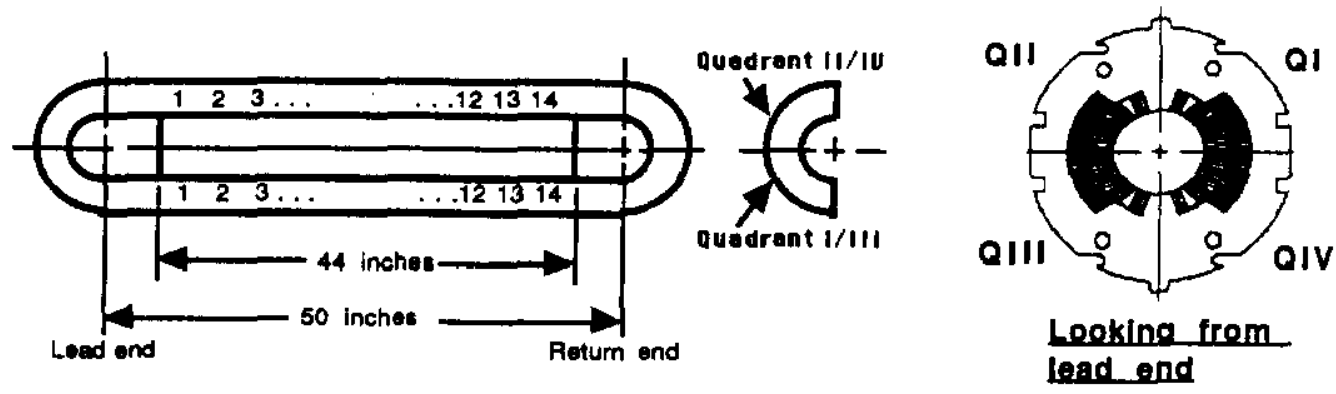

Fig. 3.

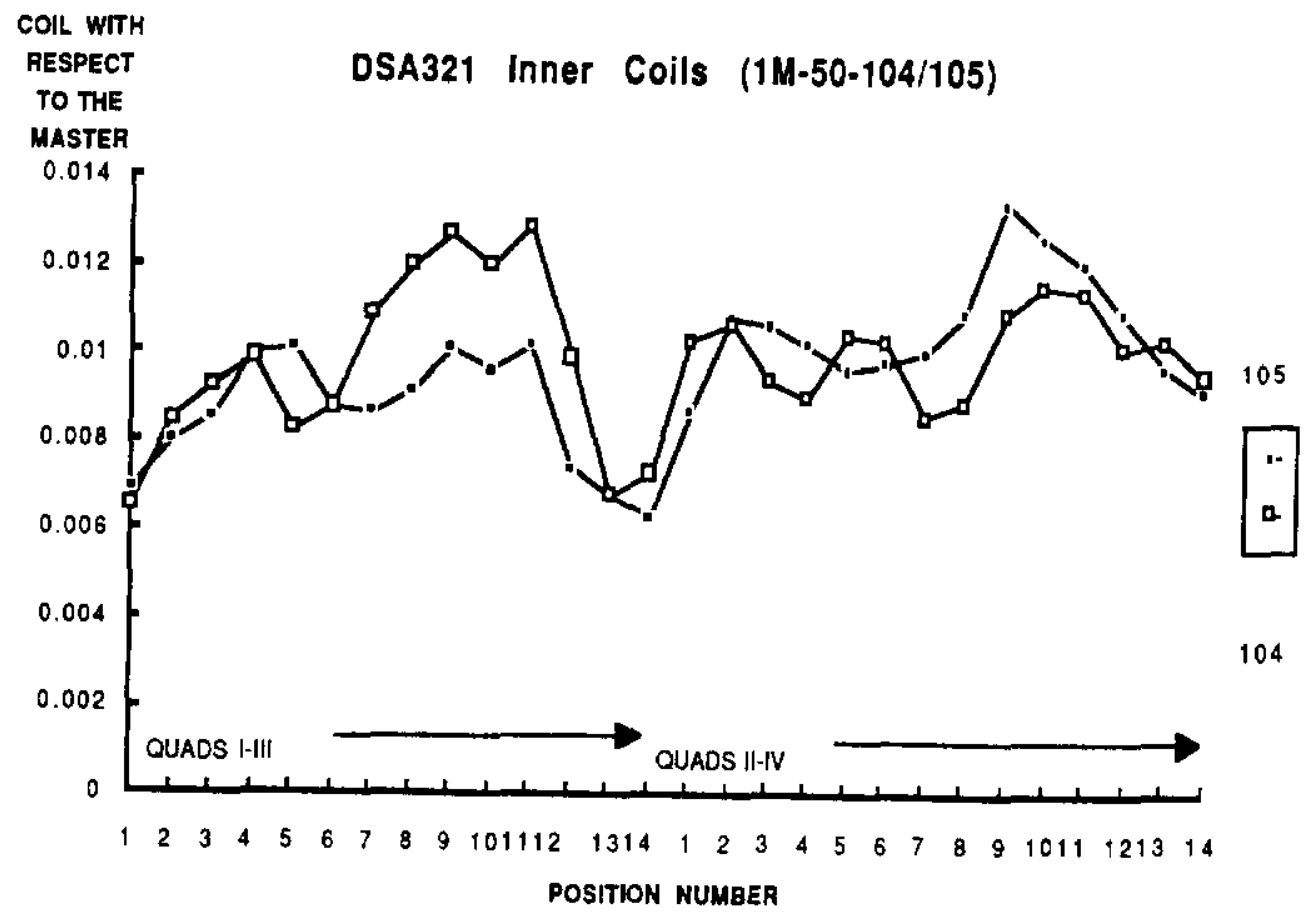

Fig. 4. 


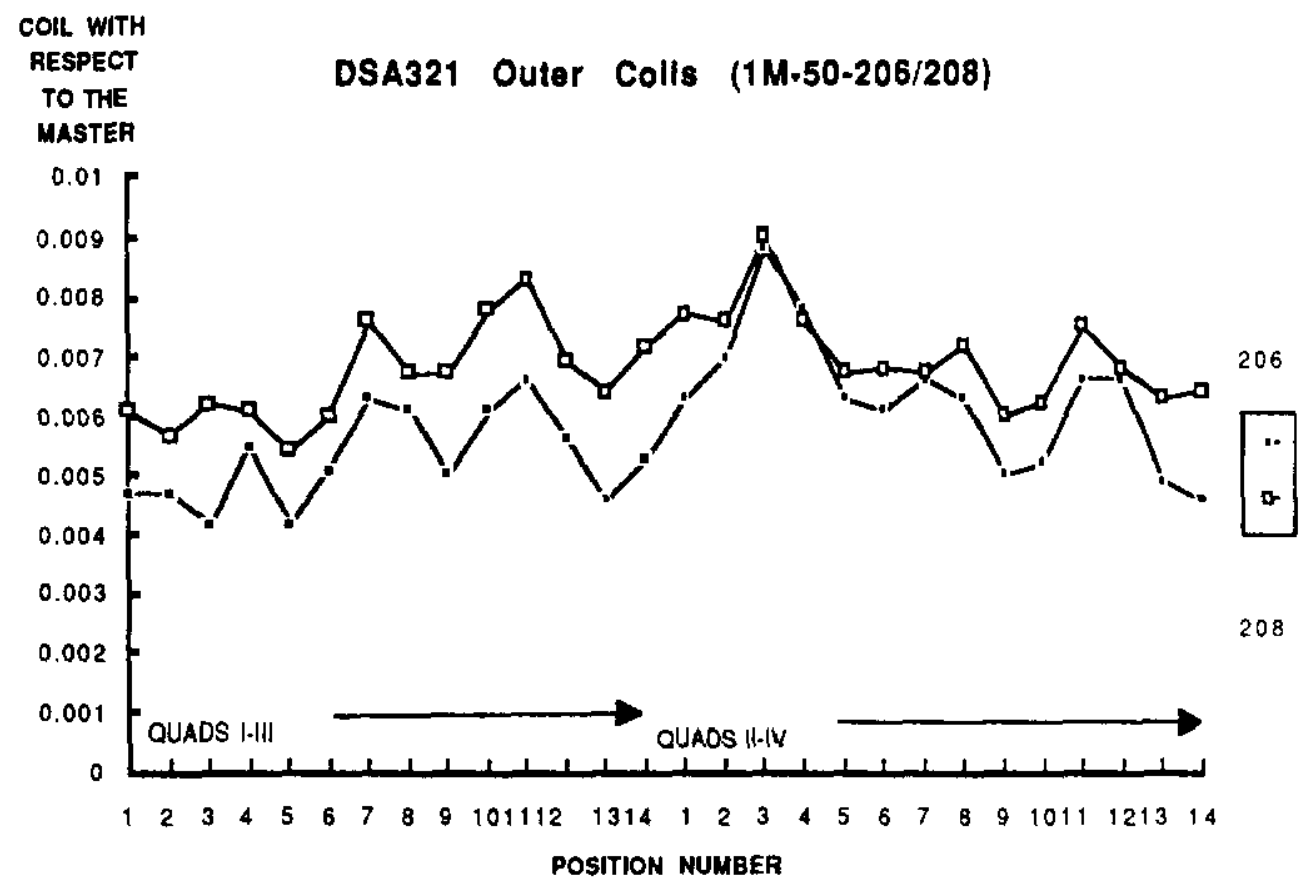

Fig. 5.

One of the original outer coils used in DSA321 (\#1M-50-205) developed a turn-to-turn short after collaring. One of the strands had apparently come out of lay during cabling. It was completely severed and "folded back" in the opposite direction over the face of the cable. This problem clearly existed before winding began. The coil was replaced by \#1M-50-208.

The ground insulation system used in magnet DSA321 is described in Reference 1 . It is similar to the $40 \mathrm{~mm}$ system. All ground insulation layers are .005 Inch Kapton. No collaring shims are used. The collaring shoe has been reintroduced. The strip heaters are made according to a design generated at SSCL. ${ }^{19}$ No strip heater was included in magnet DSA321 because these components were not yet available. All Kapton ground wrap layers were available from the manufacturer. The brass collaring shoes were not and had to be fabricated by hand.

When the collared coil was disassembled due to the turn-to-turn short mentioned above, a serious amount of darnage to the ground wrap was observed in the strain gauge area. The sharp inner corner of the block to which the outer coil transducer is mounted had cut into the Kapton ground wrap layers. Two of the three layers between the transducer block and the coil were completely severed. This problem did not exist on the $40 \mathrm{~mm}$ magnets because the transducer block, due to the different geometry, did not directly contact the ground wrap. The corners of the transducer block were rounded before reassembling the magnet. It has yet to be determined whether or not this is an acceptable long term solution.

At the time DSA321 was collared (on 12/18/90) the new 84 inch press was not complete. It was collared in the Tevatron collaring press which has insufficient capacity to collar the entire magnet at once. Upper collaring tooling was used both as upper and as lower tooling as shown in Fig. 6.

To concentrate the press load the tooling covered only somewhat more than half the coil at a time. The coil was keyed in two operations. The keys were inserted by finger and hammer.

Strain gauge data were recorded during both compressions for collar keying and during the yoking operation. The data are summarized in Fig. 7, which displays averages over the four inner and four outer coil gauges. The strain gauge pack, located at the center of the magnet, was compressed on both pressings because the collaring tooling covered more than half the coil. The final stresses after keying were 9 and $13 \mathrm{kpsi}$ in the inner and outer coils respectively. In the four days between keying and yoking, the stresses decreased by a few hundred psi. The welding 


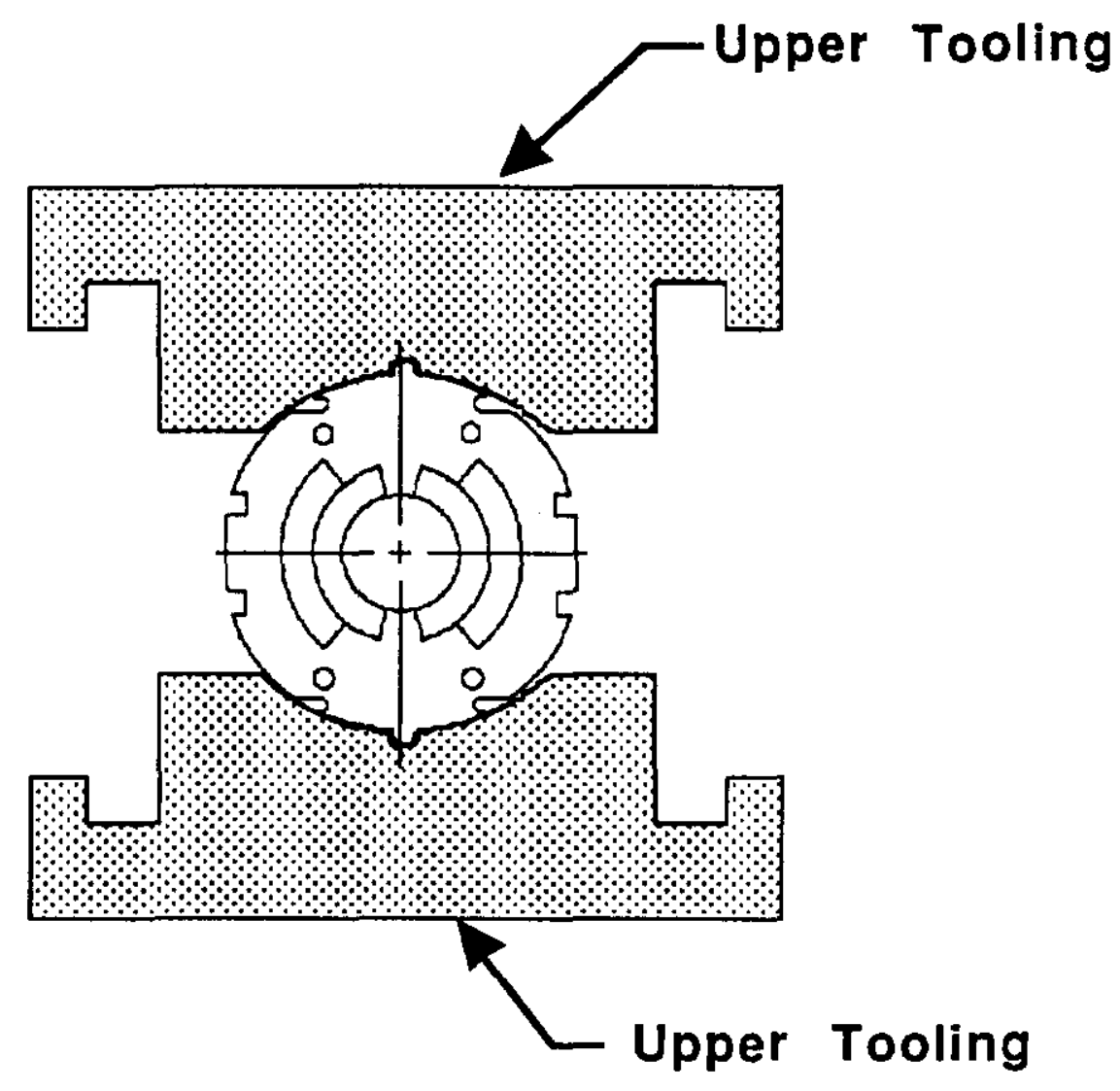

Fig. 6

of the shell around the yoke resulted in a net increase of the inner stress of $0.6 \mathrm{kpsi}$ and an apparent decrease of the outer stress by $0.1 \mathrm{kpsi}$. This is a smaller change than typically occurs in magnets with horizontally split yokes because the collars are compressed horizontally and are free to expand vertically. The last strain gauge measurement was taken eleven days after yoking. During this time there was a stress loss of $0.4 \mathrm{kpsi}$ in the inner coil and $0.3 \mathrm{kpsi}$ in the outer coil. ${ }^{3}$

Measurements were taken of the completed collared coil. Deflections on the diameters measured +.009 inches vertically and +.001 inches horizontally. Finite element analysis indicates that collar deflections should be .0081 inches vertically and near zero horizontally. The measurements are in general agreement with the calculations.

Collet style clamps are used to support the ends on Fermilab magnets. ${ }^{1}$ Azimuthal fiber G-10 was used for the collet pieces for DSA321 due to the immediate unavailability of other materials. Stainless steel was used for the outer can. This combination of materials allows preload to decrease when the magnet cools down. Other materials will be tried in future magnets.

$18000 \mathrm{lbs}$. of longitudinal force was applied to close the return end clamp. $21000 \mathrm{lbs}$. was needed for the lead end. Time did not permit the application of strain gauges to the outer surface of the end clamps.

The design calls for yoke filler laminations to be used in the end plate area to support the skin when the magnet is cooled. ${ }^{1}$ They were not used in DSA321 because the material from which they are made (high manganese steel) was not available in time.

The yokes were pressed in the newly commissioned short magnet yoke and collaring press. $125000 \mathrm{lbs}$. per linear foot were applied to the yokes before and during welding. Due to time constraints, skin gauges were not used on DSA321.

Bullets (end preload gauges) were used on the return end of DSA321. Preload screws without instrumentation were used on the lead end. Each screw or bullet was tightened to apply 


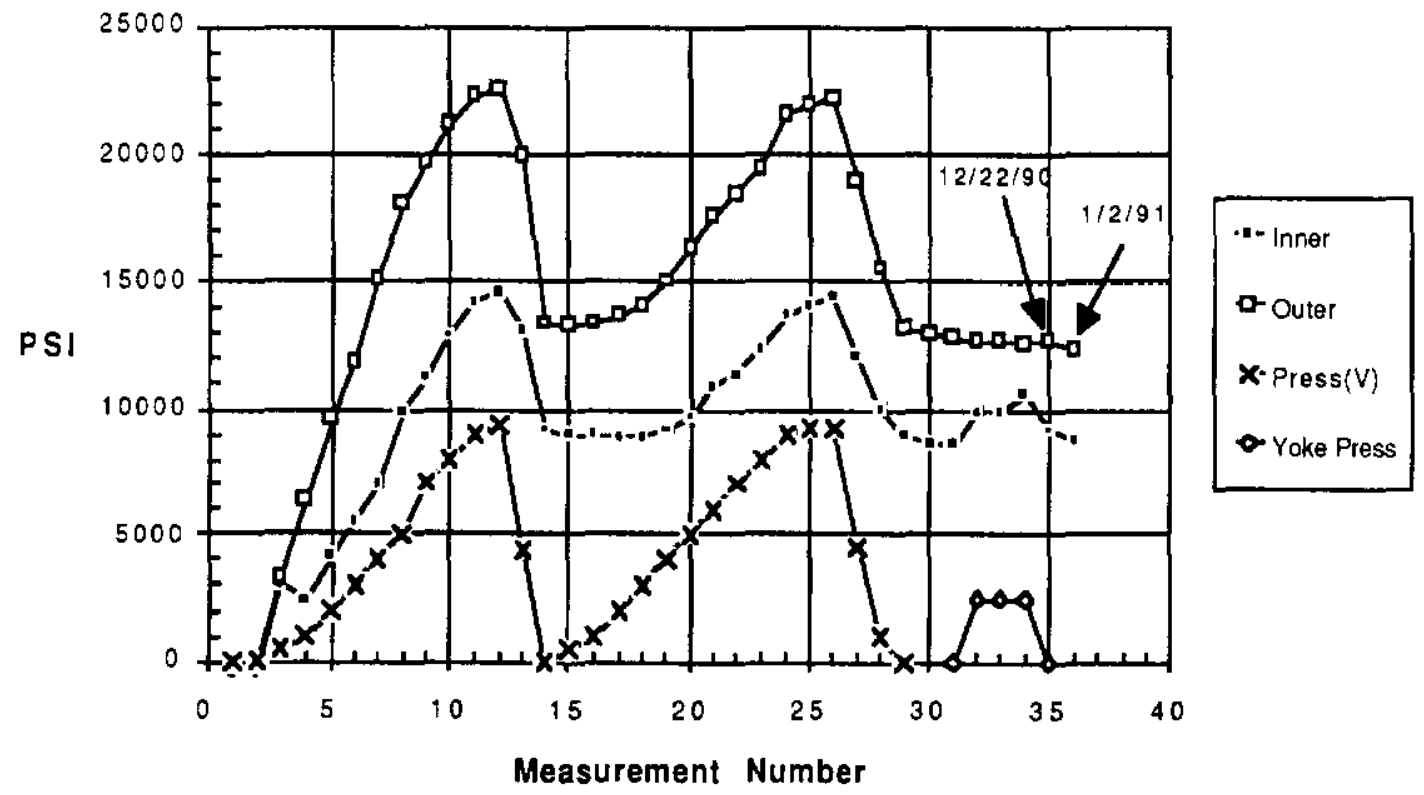

Fig. 7.

a load of approximately $200 \mathrm{lbs}$ to the end of the coil, for a total of $800 \mathrm{lbs}$. applied to each end. When the magnet is powered, the coil is expected to apply $2000-3000 \mathrm{lbs}$. of force to the bullets. This is a small percentage of the total Lorentz force. The rest is reacted by the skin through friction.

\section{DSA321 TEST RESULTS}

DSA321 was tested in January 1991.15 During the course of testing it was quenched 51 times at temperatures of $4.3,4.2,3.8$ and $3.0 \mathrm{~K}$. The quench propagation velocity was approximately $72 \mathrm{~m} / \mathrm{s}$ at short sample in the straight sections.

The first quench occurred at 7088 amps in the lower outer coil pole turn, approximately 8 $\mathrm{m} / \mathrm{s}(600 \mathrm{~mm})$ from the ramp splice. The subsequent quenches all appeared to be at or close to the short sample limit. The plateau quenches were in approximately the same longitudinal location in the pole turn, ramp splice side, of either the upper inner or lower inner coil. On the third quench the magnet reached a plateau of 7638 amps.

The magnet was then quenched at a series of ramp rates ranging from the nominal 16 amps per second to 200 amps per second. The ramp rate dependence for this magnet is rather flat relative to the preceding $40 \mathrm{~mm}$ short magnets. Another curiosity is that the high ramp rate quenches occur in the multiple turn rather than in the ramp splice.

The magnet temperature was lowered to approximately $4.2 \mathrm{~K}$ and quenched at a ramp rate of 16 amps per second. All quenches were at the standard plateau quench locations - either upper inner pole turn or lower inner pole turn - with an average of 7807 amps. The temperature was then lowered further to $3.8 \mathrm{~K}$. The magnet did not train. It was quenched four times with an average quench current of 8312 amps. All of the quenches occurred in the same location as the previous plateau quenches in the lower inner pole turn. The magnet was then warmed to room temperature for its first thermal cycle.

The magnet was recooled and the plateau currents at 4.3 and $4.2 \mathrm{~K}$ were reestablished. It was quenched five times at $4.3 \mathrm{~K}$ with an average quench current of $7609 \mathrm{amps}$. It exhibited no retraining. All quenches were standard plateau quenches located in either the upper inner or lower inner pole turn. 
The magnet was then quenched six times at 4.2K. Again, all quenches occurred in either the lower inner or upper inner pole turn with an average current of 7824 amps. It was also quenched a couple of times at 100 amps per second. Both quenches occurred in the lower inner multiple turn. The average current was 7818 amps.

Since the magnet had not shown any signs of retraining at temperatures down to $3.8 \mathrm{~K}$, the temperature was lowered to approximately 3.0K. The first quench was at 8670 amps in the fifteenth turn from the parting plane. It reached 8802 amps during the second attempt where it quenched in the lower inner pole tum. The third and final quench was at 8959 amps, located again in the fifteenth turn from the parting plane. DSA321 performed very well. After one training quench occurred in the outer coil, all quenches were at or near short sample. The magnet operates at a magnetic field above the design criteria specified for the SSC dipoles. The quench history of DSA321 is summarized in Fig. 8.

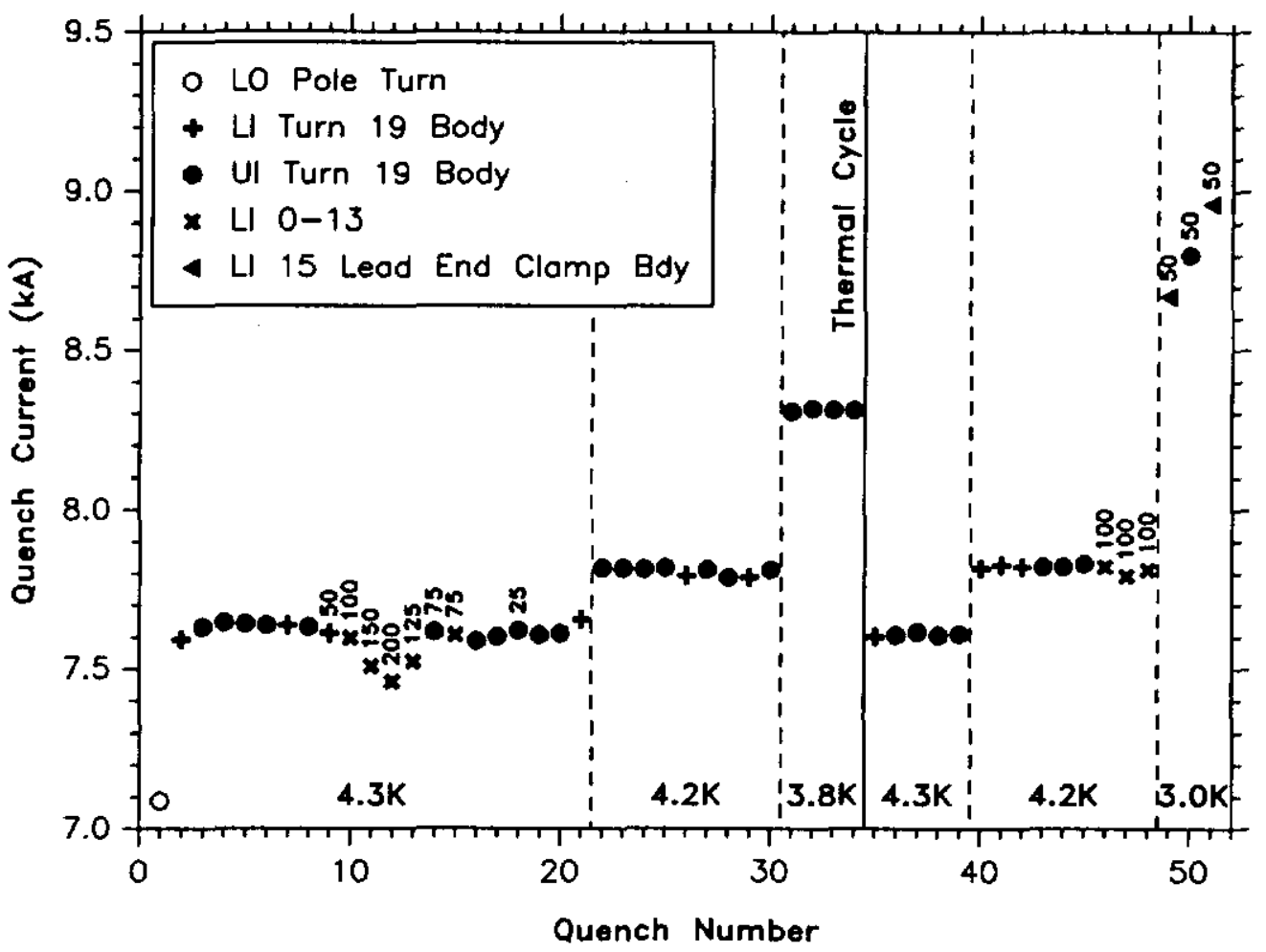

Fig. 8 DSA321 Quench History

Strain gauge data were recorded on magnet DSA321 during excitation. Figs. 9 and 10 show the inner coil and outer coil gauges respectively. The set of readings shown were taken at the end of the first $4.3 \mathrm{~K}$ cooldown. Inner coil gauges decrease to an average of about $2500 \mathrm{psi}$ at 6000 amps. Outer gauges ranged widely from 7000 to 14000 psi. Two gauges (one inner and one outer) exhibit anomalous behavior. It is likely that these gauges were not placed in the proper azimuthal position with respect to the coil. Fixturing which is used to measure the azimuthal position of the gauges was not ready in time to use for the DSA321 pack. The position of the gauges was measured in a less reliable manner.

The stress vs. current relationship for one lower outer coil strain gauge changed immediately after the first quench. It permanently moved to a position of higher stress by approximately $1000 \mathrm{psi}$. The quench had occurred in the upper outer coil pole turn in the vicinity of this strain gauge. It appears that the conductor position moved in this area as a result of the quench. 
Inner Gages

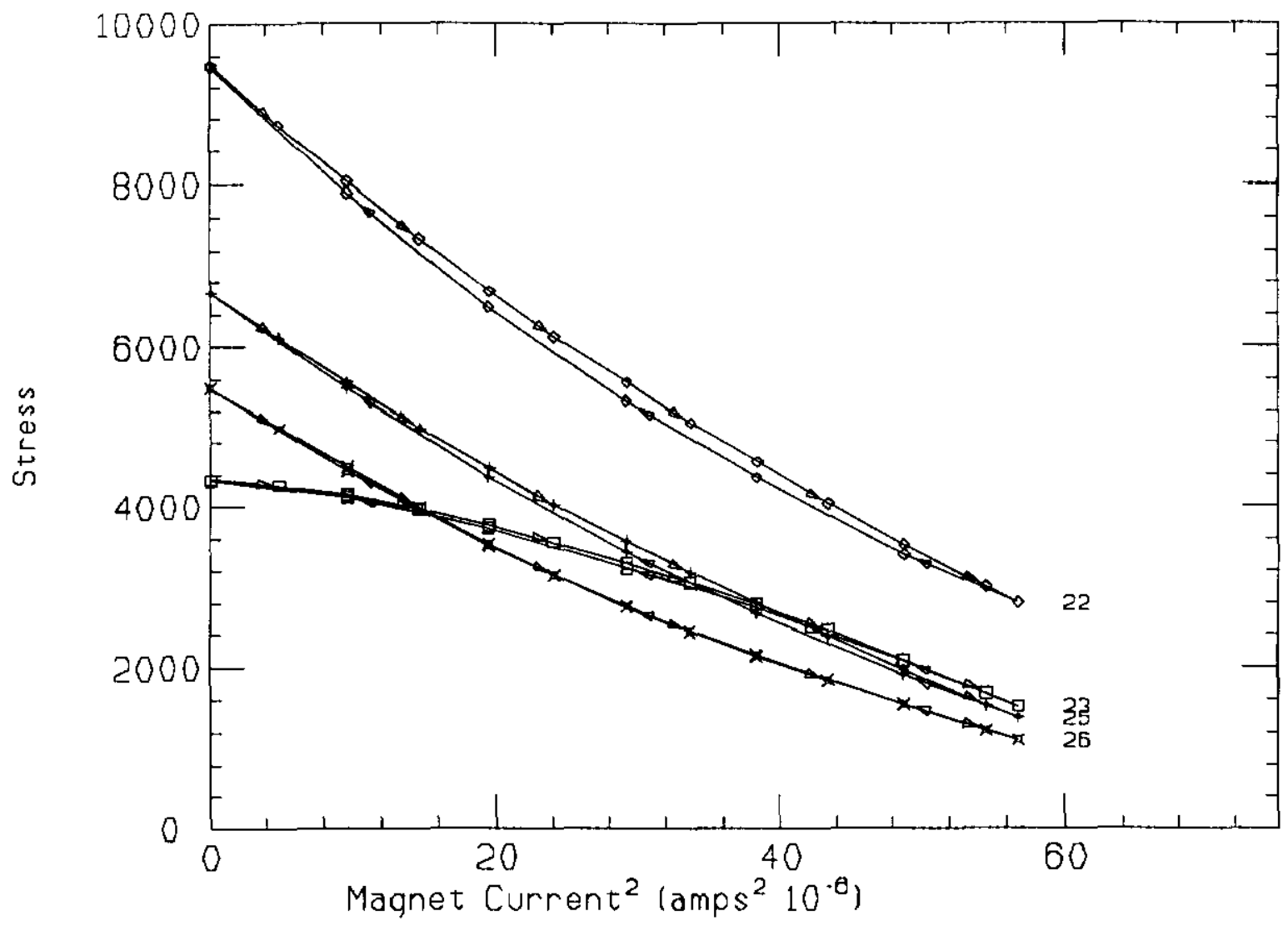

Fig. 9

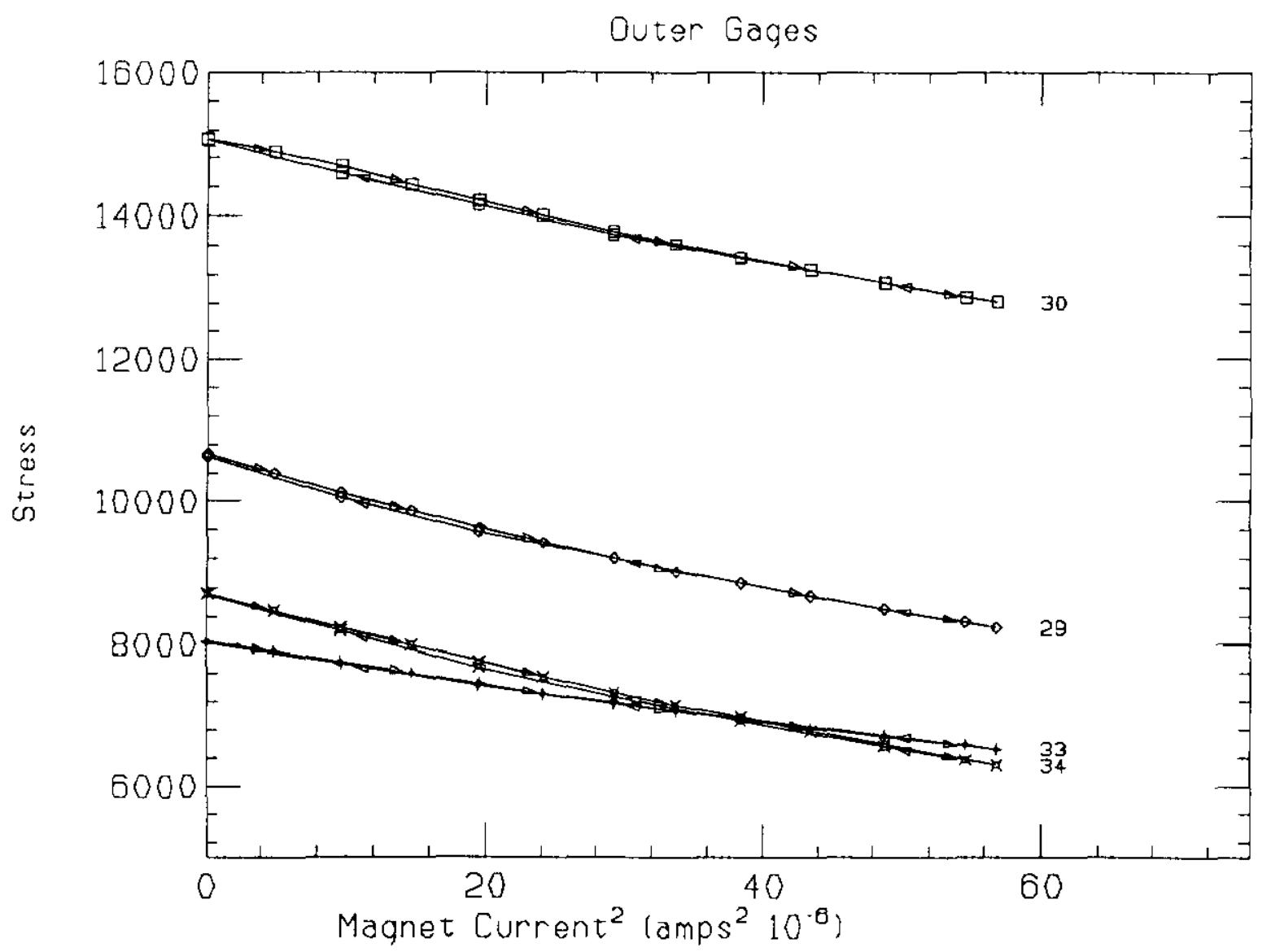

Fig. 10 
The collaring shoes ${ }^{1}$ in DSA321 had been made to a size which we now know to be short azimuthally by nearly a conductor width per quadrant. As a result, the shoe does not completely support the outer coil pole turns radially. This may have been the cause of the first training quench.

\section{DSA322 CONSTRUCTION}

Magnet DSA322 is the second $50 \mathrm{~mm}$ short magnet to be built at Fermilab. It is intended to be used for warm studies only. These include determining press shims and loads required during collaring, stresses and deflections during and after collaring, warm harmonics and stresses in the end clamps. It is not intended to be tested cold.

DSA322 was the first magnet to be collared in the new collaring and yoking press. The collaring tooling is similar to that used for the $40 \mathrm{~mm}$ magnets. 5 The press was shimmed as shown in Fig. 11 in order to cause the collared coil to be "overcompressed" by .005 inches. This allows keys to be inserted without force, thereby preventing any scoring of the keys. Scoring of the keys can result in an inconsistent key size and consequently an inconsistent relationship between preload and harmonics.5,9

The $50 \mathrm{~mm}$ collaring press has substantially stiffer components than both the long and short $40 \mathrm{~mm}$ presses. As a result, the amount of overcompression required to insert the keys was expected to be substantially less. $40 \mathrm{~mm}$ presses required as much as .020 inches or more overcompression. It is likely that most of this was due to deflections in the press itself. 17,18 The $50 \mathrm{~mm}$ press required only .005 inches of overcompression to insert the keys. This is approximately the amount that would be expected from errors due to magnet and tooling component tolerances.

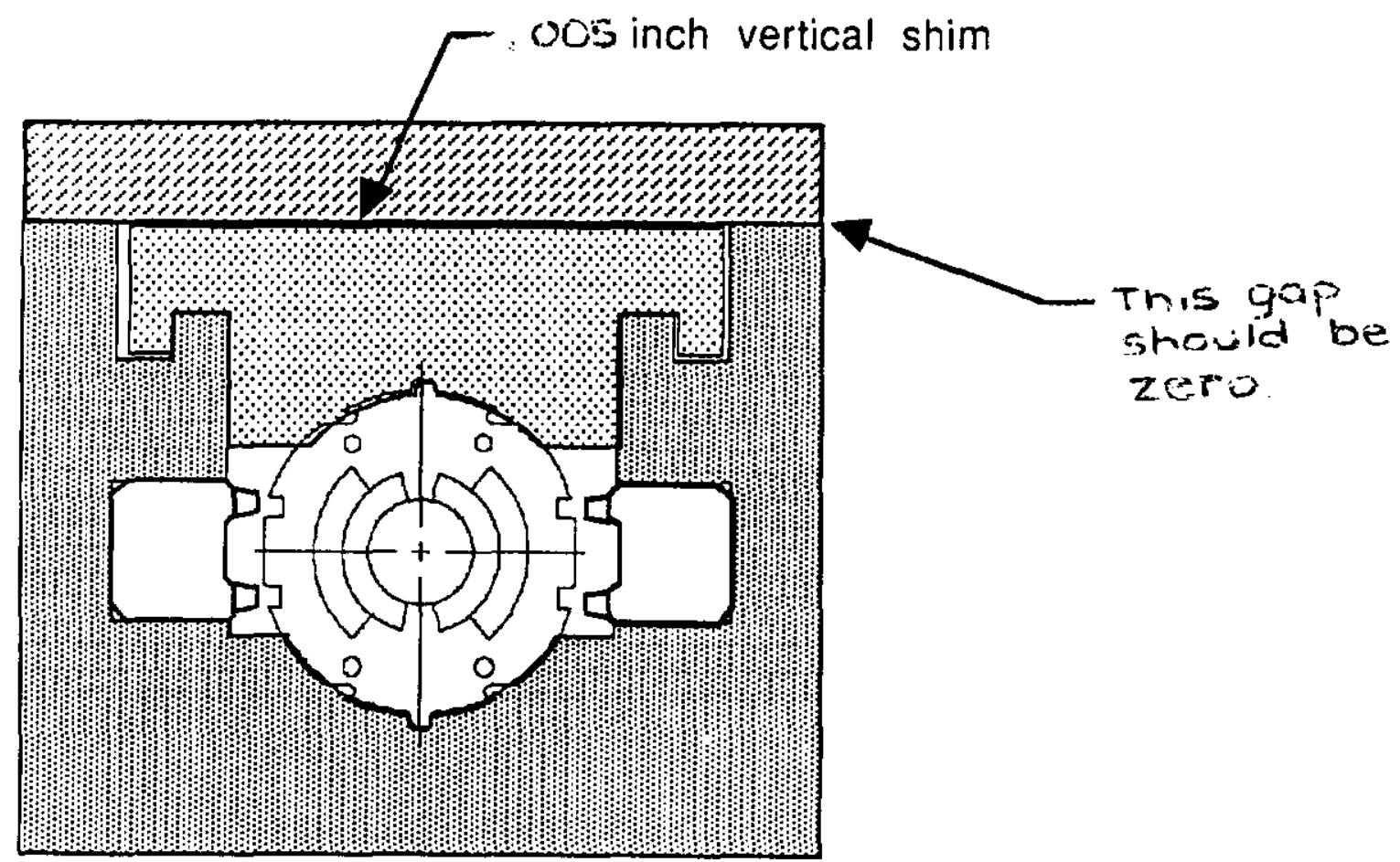

Fig. $1150 \mathrm{~mm}$ Collaring Tooling 
DSA323 is intended to be identical to DSA321 with a few exceptions. DSA323 includes strip heaters, strain gauges on the skin and strain gauges on the outside surface of the return end clamp. Time did not permit any of these features to be included on DSA321.

Coils in magnet DSA323 are approximately the same size azimuthally as the DSA321 coils. Coil preloads during collaring of DSA323 are shown in Fig. 12. They are similar to those for the previous $50 \mathrm{~mm}$ magnets.

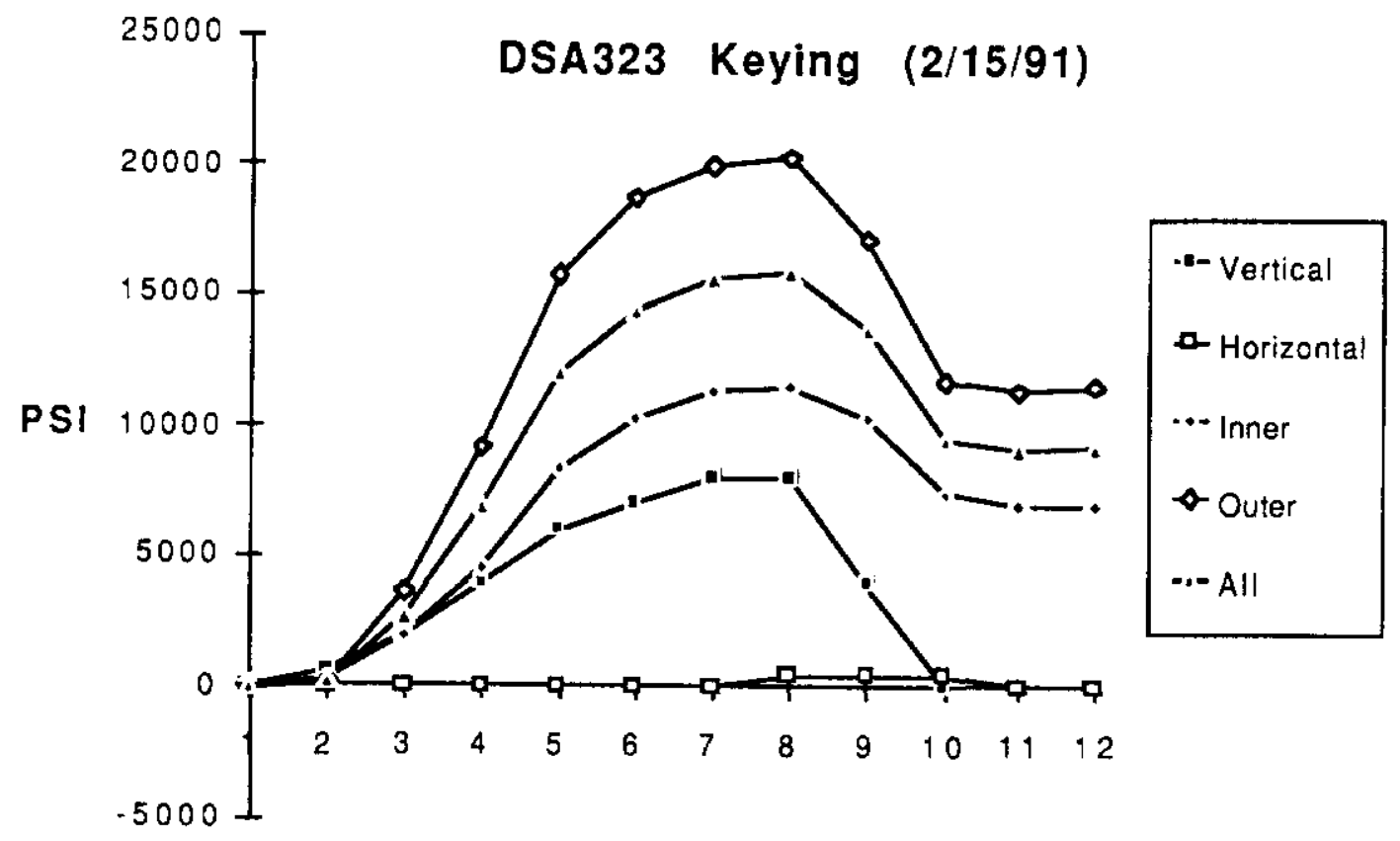

\section{Measurement Number}

Fig. 12

\section{CONCLUSION}

A series of one meter SSC dipoles are being produced at Fermilab. Their initial purpose is to prove that the $50 \mathrm{~mm}$ design is acceptable before full scale models are built. Another purpose of the short model program is to test alternatives which could improve the performance of the established design. Alternatives and improvements can be implemented quickly and inexpensively in short models. Models are being built which are accomplishing the first objective. Further models will explore design alternatives. The short magnet program is equipped to provide these essential functions to support the long SSC dipole manufacturing process.

\section{REFERENCES:}

1. Edited by E. Pewitt, "50mm Collider Dipole Magnet Requirements and Specifications" (yellow book).

2. J.S. Brandt, N.W. Bartlett, R.C. Bossert, J.A. Carson, G.C. Lee, Fermi National Accelerator Laboratory, J.M. Cook , Argonne National Laboratory, S. Caspi, Lawrence Berkeley Laboratory, M.A. Gordon, F. Nobrega, Superconducting Supercollider Laboratory, "Coil End Design for the SSC Collider Dipole Magnet", to be presented at the Particle Accelerator Conference, San Francisco, California, May 6-9, 1991. 
3. J. Strait, "DSA321 Yoking and Collaring: Strain Gauge Data", Fermilab Technical Support Technical Note \#TS-SSC 91-026.

4. M. Anarella, "1.8m, 50mm SSC Magnet DSA207 Summary of Construction Details", 366-7 (SSC-MD-256).

5. R.C. Bossert, J.S. Brandt, J.A. Carson, C.E.Dickey, I.Gonczy, W.A. Koska and J. Strait, SSC 40mm Short Model Construction Experience, in: "Supercollider 2", M. McAshan, ed., Plenum Press, New York, 1990.

6. M. Gordon and R. Bossert, "SSC 50mm Yoke Stacking Design", Fermilab Technical Support Technical Note \#TS-SSC 91-034.

7. R. Bossert and J. Brandt, "SSC End Part Modifications", Fermilab Technical Support Technical Note \#TS-SSC 90-042.

8. M. Wake, T.S. Jaffery and M.J. Lamm, "Periodic Remnant Field in SSC 50mm Dipole", Fermilab Technical Support Technical Note TS-SSC 91-032.

9. J. Strait, "Prestress, Ovality and Multipoles in DSS Magnets", presented at the July 1989 MSIM, Fermi National Accelerator Laboratory.

10. R. Bossert, "DSA321 Construction Summary", Technical Support Technical Note \#TS-SSC 91-040.

11. R. Bossert, "DSA321 Construction Review", Technical Support Technical Note \#TS-SSC 91-007.

12. R.C. Bossert, J.S.Brandt, J. A. Carson, H. J. Fulton, G. C. Lee, Analytical Solutions to SSC Coil End Design, in: "IISSC, Supercollider 1", M. McAshan, ed., Plenum Press, New York (1989).

13. J.M. Cook, Argonne National Laboratory, "An Application of Differential Geometry to SSC Magnet End Design", Fermilab TM-1663, SSC Laboratory SSCL-N-720.

14. J. Cook, Argonne National Laboratory, "Strain Energy Minimization in SSC Magnet Winding", Fermilab TM-1703, SSC Laboratory \#SSCL-N-744.

15. S.A. Gourlay, "Summary of DSA321 Quench Performance", Fermilab Technical Support Technical Note \#TS-SSC 91-029.

16. J. A. Carson, E. J. Barczak, R. C. Bossert, J. S. Brandt, G. A. Smith, SSC Dipole Coil Production Tooling, in: "IISSC Supercollider 1", M. MCAshan, ed., Plenum Press, New York, 1989.

17. R. Bossert, "SSC $40 \mathrm{~mm}$ Long Magnet Collaring Problems", Fermilab Technical Support Technical Note \#TS-SSC 91-081.

18. R. Bossert, "40mm SSC Long Press Platten Deflection", Fermilab Technical Support Technical Note \#TS-SSC 91-054.

19. C. Haddock, B. Aksel, G. Snitchler, J. Jayakumar, F. Meyer, G. Tool (SSCL) and R. Bossert, M. Lamm, J. Strait (Fermilab), "SSC Dipole Quench Protection Heater Development", to be presented at the Magnet Technology-12 Conference, Leningrad, USSR, June 23-28, 1991. 